\title{
CHILDREN'S FRIENDLY EDUCATION BASED ON TRADITIONAL GAMES IN TAMAN MUDA IBU PAWIYATA ELEMENTARY SCHOOL
}

\author{
Maya Kartika Sari, Suminto A. Sayuti, Pardjono \\ Universitas PGRI Madiun, Universitas Negeri Yogyakarta \\ mayakartika84@gmail.com
}

\begin{tabular}{l} 
Article History \\
\hline accepted 09/07/2018 \\
approved 01/08/2018 \\
published 17/09/2018
\end{tabular}

\section{Keywords}

Kata kunci 3-5 kata dengan tanda pisah koma (,) $[10 \mathrm{pt}]$

\begin{abstract}
Penelitian ini bertujuan untuk mengetahui pendidikan ramah anak berbasis dolanan anak tradisional di SD Taman Muda Ibu Pawiyata Yogyakarta. Jenis penelitian ini bersifat kualitatif dengan menggunakan pendekatan studi kasus. Subjek penelitian yakni kepala sekolah, pamong, siswa, dan orang tua. Penentuan subyek penelitian dilakukan dengan teknik purposive sampling. Teknik pengumpulan data menggunakan observasi, wawancara, dan dokumentasi. Analisis data dalam penelitian menggunakan Model Miles dan Huberman yaitu pengumpulan data, reduksi data, penyajian data, dan kesimpulan. Hasil penelitian menunjukkan bahwa pendidikan ramah anak berbasis dolanan anak tradisional di SD Taman Muda Ibu Pawiyata Yogyakartatelah berjalan dengan baik dan dapat mengeksplorasi potensi siswa. Guru atau pamong melaksanakan pembelajaran melalui metode bermain atau dolanan, guru menciptakan suasana yang kondusif dalam pembelajaran, guru berupaya mengembangkan bakat minat anak secara maksimal tanpa beban paksaan, guru mencurahkan kasih sayang kepada siswa secara utuh, guru memberikan perhatian bagi mereka yang lemah dalam proses belajar melalui bimbingan belajar intens. Pendidikan ramah anak berbasis dolanan anak tradisional di SD Taman Muda Ibu Pawiyata Yogyakarta yang dilakukan seperti lepetan, cublak-cublak suweng, jamuran, dakon, jaranan, galasin, dimana dapat menumbuhkan karakter positif pada anak yaitu menumbuhkan toleransi antar teman, saling membantu, demokratis, jujur dan disiplin dalam mematuhi peraturan permainan, dan menumbuhkan rasa cinta pada budaya yang ada dan melestarikan dolanan anak tradisional agar tetap berkelanjutan. Pendidikan ramah anak berbasis dolanan anak tradisional di SD Taman Muda Ibu Pawiyata Yogyakarta mendapatkan dukungan penuh dari orangtua dan pihak sekolah sehingga implementasinya dapat maksimal dan terkondisi dengan baik.
\end{abstract}

Social, Humanities, and Education Studies (SHEs): Conference p-ISSN 2620-9284 Series e-ISSN 2620-9292

https://jurnal.uns.ac.id/shes 


\section{PENDAHULUAN}

Pendidikan ramah anak adalah suatu pendekatan dalam proses pembelajaran yang mengutamakan nilai humanistik yang disebut juga mendidik anak dengan pendekatan kasih sayang. Anak tidak lagi dijadikan obyek pembelajaran namun sebagai subyek pembelajaran, dimana orang tua dan guru hanya sebagai pengarah dan pembimbing bagi mereka. Dengan kata lain bahwa pendidikan ramah anak adalah pengembangan pembelajaran yang humanistik pada anak dan berusaha mengubah suasana belajar menjadi lebih menyenangkan dengan memenuhi atau mendukung hak anak serta memadukan potensi fisik, psikis dan mental anak dengan pendekatan kasih sayang baik dalam keluarga, sekolah, masyarakat, dan negara.

Konsep pendidikan ramah anak terlahir karena adanya UU No.23 Tahun 2002 tentang perlindungan anak sebagai implementasi dari Konvensi Hak Anak (KHA) di Indonesia. Konvensi Hak Anak (KHA) adalah konvensi Perserikatan Bangsa-Bangsa (PBB) yang melindungi hak-hak anak. Undang-undang perlindungan anak adalah salah satu bagian dari mengoperasionalkan Konvensi Hak Anak (KHA). Undang-Undang Perlindungan Anak merupakan salah satu Undang-undang mengenai hak-hak anak yang menjelaskan secara rinci tentang perlindungan anak. Perlindungan adalah salah satu dari hak-hak anak yang esensial dan penting untuk dijalankan. Perlindungan ini meliputi perlindungan terhadap kekerasan, eksploitasi, diskriminasi, dan penelantaran. UU Perlindungan Anak memberikan kerangka atau payung yang sangat bermanfaat untuk memberikan perlindungan bagi sebagian besar anak-anak rentan/rawan. Salah satu kekuatan dari UU ini adalah adanya sangsi yang jelas dan tegas terhadap siapa saja yang melakukan pelanggaran terhadap hak anak. Pendidikan Ramah Anak merupakan pendidikan yang mengedepankan rasa riang, bahagia, aman, sehat, menarik, efektif, menghormati hak anak, asah, asih, asuh, nyaman, aspiratif dan komunikatif.

Pendidikan ramah anak yang diterapkan di SD Taman Muda Ibu Pawiyata Yogyakarta menggunakan dolanan anak tradisional. Hal ini dikarenakan anak-anak akan merasa senang apabila pendidikan dilakukan dengan bermain, sehingga menghadirkan suka cita dan bahagia. Permainan tradisional adalah segala perbuatan baik mempergunakan alat atau tidak, yang diwariskan turun temurun dari nenek moyang, sebagai sarana hiburan atau untuk menyenangkan hati. (Misbach, 2006: 6). Dolanan anak tradisional dapat mempengaruhi aspek perkembangan anak, (Ifa $\mathrm{H}$. Misbach, 2006: 7), yakni antara lain :

a. Aspek motorik yakni melatih daya tahan, daya lentur, sensorimotorik, motorikkasar, dan motorik halus.

b. Aspek kognitif yakni mengembangkan daya imaginasi, kreativitas, problem solving dalam menghadapi sesuatu

c. Aspek emosi yakni mengendalikan dan mengontrol emosi dan mengasah empati kepada orang lain

d. Aspek bahasa yakni mempengaruhi kemampuan berbahasa untuk berkomunikasi, mengenalkan bahasa Jawa untuk pelestarian budaya

e. Aspek sosial, yakni menjalin relasi, kerjasama, melatih kematangan sosialdengan teman sebaya dan meletakkan pondasi untukmelatih keterampilan sosialisasi berlatih peran denganorang yang lebih dewasa/masyarakat.

f. Aspek spiritual yakni melalui dolalan tradisional maka siswa akan menyadari keterhubungan dengan sesuatu yangbersifat agung (transcendental)

g. Aspek ekologis yakni dolanan tradisional tidak lepas dengan lingkungan alam sekitar, sehingga siswa diharapkan mampu memahami pemanfaatan elemen-elemen alam sekitarsecara bijaksana

h. Aspek nilai-nilai/moral yakni menghayati nilai-nilai moral yang diwariskan darigenerasi terdahulu kepada generasi selanjutnya 
Dolanan anak Tradisional sangat dekatdengan unsur-unsur alam, baik dalam hal tempat bermain maupun alat-alat permainan yangdigunakan, dengan demikian, kedekatan dan keterlibatan dengan alamini mampu menumbuhkan nilai-nilai positif dalamberinteraksi dengan alam itu sendiri. Bisadikatakan seluruh permainan tradisionalyang ada ini menggunakan unsur-unsur alamsebagai media/alat permainan mereka. Dolanan tradisional dapat dilakukan di lapangan dengan terik matahari, menggunakan batu, kayu dan bambu sebagai alat permainan. Ketika bermain anak-anak berlarian kesana kemari, melombat, berteriak, dan bercanda tawa dengan bersukacita. Sedangkan permainan modern biasanya bertempat diruangan khusus yang nyaman dan menggunakan peralatan yang canggih. (Mulyani, 2016: 15)

Namun sayangnya dolanan anak tradisional ini telah tergerus oleh kecanggihan teknologi dan perkembangan zaman. Anak-anak lebih senang bermain gadget, game online dan menonton TV sehingga memunculkan sikap individual, lebih senang menyendiri, asyik dengan dunianya sendiri, bermain sendiri tanpa bantuan orang lain, agresif, kurang bersosialisasi dan berkomunikasi dengan lingkungan sekitar, anak menjadi pribadi yang egois, pemarah, dan kurang peduli lingkungan sekitar terutama untuk anak usia sekolah dasar. Hal ini perlu disikapi oleh sekolah dan orangtua dengan menerapkan pendidikan ramah anak berbasis dolanan anak tradisional di sekolah. SD Taman Muda Ibu Pawiyata Yogyakarta berupaya menerapkan dolanan anak tradisional sebagai pendidikan ramah anak di sekolah.

Penelitian terdahulu yang mendasari penelitian ini adalah penelitian dari Penelitian terdahulu lainnya dari Bintarto Wicaksono (2014) yang berjudul Transformasi Budaya Dalam Dolanan Anak Taman Siswa Yogyakarta, yang menyatakan dalam penelitiannya bahwa Dolanan anak merupakan satu bentuk kesenian rakyat Jawa yang menggunakan bahasa dan simbol sebagai sarana piwulang (pembelajaran) dan piweling (nasihat). Dolanan anak termasuk dalam budaya folklor, karena diperoleh dari tradisi lisan dan anonym serta banyak tersebar di wilayah Jawa khususnya Yogyakarta pada tataran ndeso dan mancanegara. Perkembangan dolanan anak di Yogyakarta, salah satunya ada di Perguruang Nasional Taman Siswa Yogyakarta dengan mengembangkan kesenian rakyat dolanan anak menjadi kesenian untuk media pendidikan dan menjadi kesenian populer di masyarakat Yogyakarta. Perubahan demi perubahan terus berjalan, baik dari segi ide penciptaan, bentuk, fungsi maupun media. Perubahan dolanan anak di Taman Siswa juga tidak bisa terlepas dari perkembangan zaman, baik dari segi teknologi maupun perkembangan pola konsumsi masyarakat sekarang ini. Secara sadar atau tidak sadar, secara terstruktur maupun tidak terstruktur dan secara bertahap dalam kurun waktu yang cukup lama, Taman Siswa melalui para pamong-pamongnya turut metransformasikan dolanan anak dari folklor menjadi pop culture.Penelitian yang dilakukan oleh Bintarto Wicaksono memaparkan tentang transformasi budaya dolanan anak di taman Siswa yang dulu hanya sebuah warisan lisan (folklor) menjadi pop culture yang menjadi budaya populer di masyarakat.Penelitian lain dari Eka Nugrahastuti, dkk. (2015) dengan judul Nilai-Nilai Karakter Pada PermainanTradisional, menyatakan bahwa dolanan anak tradisional mengandung nilai-nilai karakter, diantara nya dolanan anak tradisional sepertigobag sodor, cublak-cublak suweng, dan engklek. Nilai-nilaiyang terkandung dalam dolanan tradisional gobag sodor dapat antara lain adalah nilaikejujuran, nilai sportivitas, nilai kerjasama, nilai pengaturan strategi dan nilai kepemimpinan.Nilai-nilai yang terkandung pada dolanan tradisional cublak-cublak suweng adalah nilaikerjasama, nilaikerukunan, dan nilaikreatifitas. Nilai-nilai yang terkandung dalam dolanan engklek yaitu melatih kedisplinan, ketangkasan, bersosialisi dan kesehatan

Berdasarkan penelitian terdahulu maka peneliti ingin mengetahui lebih mendalam pendidikan ramah anak berbasis dolanan anak tradisional di SD Taman Muda Ibu Pawiyata Yogyakarta 


\section{METODE PENELITIAN}

Jenis penelitian. Jenis penelitian ini bersifat kualitatif dengan menggunakan pendekatan studi kasus. Tujuannya yakni peneliti berpartisipasi langsung dalam penelitian dilapangan untuk mendapatkan data yang valid dan reliabel sehingga dapat dipertanggungjawabkan, selain itu agar peneliti dapat meneliti lebih mendalam mengenaai pendidikan ramah anak berbasis dolanan anak tradisional di SD Taman Muda Ibu Pawiyata Yogyakarta. Subjek penelitian dalam penelitian ini yakni kepala sekolah, guru, siswa, dan orang tua. Penentuan subyek penelitian dilakukan dengan teknik purposive sampling. Teknik pengumpulan data menggunakan observasi, wawancara, dan dokumentasi. instrumen penelitian dalam bentuk pedoman wawancara, pedoman observasi, catatatan lapangan dan gambar foto sebagai dokumentasi penelitian. Analisis data dalam penelitian menggunakan Model Miles dan Huberman yaitu pengumpulan data, reduksi data, penyajian data, dan kesimpulan.

\section{HASIL PENELITIAN DAN PEMBAHASAN}

Hasil penelitian menunjukkan bahwa pendidikan ramah anak berbasis dolanan anak tradisional di SD Taman Muda Ibu Pawiyata Yogyakartatelah berjalan dengan efektif, dapat mengeksplorasi potensi siswa, terciptanya kondisi pembelajaran yang kondusif, membahagiakan, menyenangkan dan pengembangan bakat minat anak semakin maksimal. Pendidikan ramah anak berbasis dolanan anak tradisionaldi SD Taman Muda Ibu Pawiyata Yogyakartadilakukan dengan cara :

1. Sekolah memfasilitasi siswa untuk bereksplorasi dalam kegiatan pembelajaran.

2. Kepala sekolah memberikan bimbingan, pengarahan dan terbuka untuk konsultasi guru apabila ada permasalahan menyangkut siswa.

3. Guru memberikan ruang gerak siswa untuk mengembangkan kemampuan dan bakatnya sehingga siswa dapat memaksimalkan potensinya.

4. Guru melaksanakan pembelajaran secara berkelompok dalam komunitas belajar, sehingga tidak membedakan siswa yang pintar dan siswa yang kurang pintar.

5. Guru tidak pilih kasih terhadap siswa dan memberikan bimbingan kepada siswa yang lemah belajar

6. Guru senantiasa menciptakan pembelajaran yang kondusif dan menyenangkan melalui dolanan anak.

7. Guru berupaya untuk mengoptimalkan tumbuh kembang siswa

8. Guru berupaya menempatkan siswa sebagai pusat pembelajaran dan mengutamakan keaktifan belajar siswa dalam pembelajaran.

9. Sekolah mengaplikasikan dolanan anak tradisional di jam pulang sekolah dan ketika kegiatan intrakurikuler di sekolah.

10. Sekolah mengupayakan siswa untuk mengikuti kegiatan dolanan anak tradisional sebagai pendidikan ramah anak untuk menumbuhkan karakter positif pada siswa.

11. Dolanan anak tradisional dapat menjadi ruang ekspresi siswa dalam pembelajaran

12. Dolanan anak memberikan kebebasan kepada anak sebagai kodratnya anak yakni bebas merdeka

13. Sekolah melibatkan orangtua atau wali siswa. Pihak Sekolah senantiasa berinteraksi dan berkomunikasi dengan baik kepada orangtua atau wali siswa, sekolah senantiasa menginformasikan segala bentuk kegiatan siswa, permasalahan yang muncul di sekolah, dan sekolah secara intensif melakukan parenting yang mengundang orangtua siswa, tujuannya yakni melibatkan orangtua dalam pola pendidikan anak 
14. Guru senantiasa mendorong partisipasi anak dalam belajar, dengan memberikan kebebasan anak dalam berkreasi dan mengeluarkan pendapat.

15. Guru memiliki minat untuk memberikan layanan pendidikan yangterbaik dengan tidak membeda-bedakan status sosial siswa

16. Guru membiasakan siswa bertoleransi dengan teman-temannya dengan menghormati yang lebih tua dan menyayangi yang lebih muda.

Pendidikan ramah anak melalui permainantradisional SD Taman Muda lbu Pawiyata Yogyakarta dilakukan dengan menerapkan berbagai jenis permainan tradisional yaitu dakon, jamur, cublak cublak suweng, jaranan, galasin, bentik, dan egrang. Permainan tradisional yang dilaksanakan di sekolah Taman Siswa dimainkan secara gembira dan terus menerus. Guru atau pamong melaksanakan pembelajaran melalui metode bermain atau dolanan, guru menciptakan suasana yang kondusif dalam pembelajaran, guru berupaya mengembangkan bakat minat anak secara maksimal, guru mencurahkan kasih sayang kepada siswa secara utuh, guru memberikan perhatian bagi mereka yang lemah dalam proses belajar melalui bimbingan belajar intens. Selain itu pengaruh pada siswa yaknianak-anak merasa sangat termotivasi dan menumbuhkan rasa empati, toleransi dan karakter positif pada diri siswa.

Pendidikan ramah anak berbasis dolanan anak tradisional di SD Taman Muda lbu Pawiyata Yogyakarta yang dilakukan seperti lepetan, cublak-cublak suweng, jamuran, dakon, jaranan, galasin, dimana dapat menumbuhkan karakter positif pada anak yaitu menumbuhkan toleransi antar teman bermain, saling membantu antara teman, demokratis, jujur dan disiplin dalam mematuhi peraturan permainan, dan menumbuhkan rasa cinta pada budaya yang ada dan melestarikan dolanan anak tradisional agar tetap berkelanjutan.

\section{SIMPULAN}

Pendidikan ramah anak berbasis dolanan anak tradisional di SD Taman Muda lbu Pawiyata Yogyakarta telah berjalan dengan baik dan perlu selalu ditingkatkan kelestariannya. Pendidikan ramah anak dilakukan dengan permainan tradisional yang dapat membangkitkan jiwa merdeka anak, melatih dan mengasah Wirogo (melalui raga). wiroso (melalui perasaan), dan wiromo (dengan ritme kehidupan atau bioritmis kehidupan dalam budi pekerti). Selain itu permaianan tradisional yang dilaksanakan di sekolah dapat menumbuhkan karakter yang positif bagi siswa diantaranya sikap saling menghargai dan menghormati, sikap kerjasama yang baik, sikap jujur, sikap bertanggungjawab, sikap peduli sosial dan lingkungannya serta sikap mencintai dan melestarikan kebudayaan

Sekolah SD Taman Muda Ibu Pawiyata Yogyakarta harus menyebarkan dan membangkitkan semangat dolanan anak tradisional ke sekolah-sekolah lainnya dikarenakan dolanan anak tradisional adalah ajaran Ki Hadjar Dewantara yang harus senantiasa dilestarikan melalui berbagai event-event dan program kegiatan yang dapat menumbuhkan rasa cinta pada dolanan anak tradisional.

\section{DAFTAR PUSTAKA}

Bintarto Wicaksono. (2013). Transformasi Budaya Dalam Dolanan Anak Taman Siswa

Yogyakarta. Laporan Penelitian. Jakarta : Universitas Budi Luhur

Danandjaya, James. 2007. Folklor Indonesia, IImu Gosip, Dongeng dan Iain-lain.. Jakarta : Pustaka Utama Grafiti

Dewantara, Ki Hajar. 2009. Menuju Manusia Merdeka. Yogyakarta : Leutika 
SHEs: Conference Series 1 (1) (2018) 495-500

Ifa H. Misbach. 2006. Peran Permainan Tradisional yang Bermuatan Edukatif dalamMenyumbang Pembentukan Karakter dan Identitas Bangsa. Laporan Penelitian Universitas Pendidikan Indonesia.

Muslich, Mansur. 2011. Pendidikan Karakter:Menjawab Tantangan Krisis Multidimensional.Jakarta: Bumi Aksara

Maya kartika, Suminto Sayuti. Patterns of Child Friendly Education through the among system and Traditional Game Teachings of Ki Hadjar Dewantara. Proceding International Conference, hal 201-205, pada tanggal 21-22 April 2018

Miles, M. B. \& Huberman, M. (1994). Qualitative data analysis: an expanded sourcebook- (2end). SAGA Publication: International Educational and Professional Publisher Thousand Oaks London New Delhi. 